\title{
Active Faults: Geomatics and Soft Computing Techniques for Analysis, Monitorig and Risk Prevention in Central Tyrrhenian Calabria (Italy)
}

\author{
VINCENZO BARRILE, ANTONINO Fotia \\ DICEAM - Civil, Energy, Environment and Material Engineering Department \\ Mediterranea University \\ Località Feo di Vito 89124 Reggio Calabria
}

ITALY

\begin{abstract}
Geodynamic phenomena monitoring is constantly evolving; however, earthquake prediction is still impossible. The acquired big data over time availability allows us to create specific models to simulate these phenomena. Generally, earthquakes happen in clusters, and major aftershocks are preceded by other small aftershocks. Applying mathematical models to the swarm measurement data provides the seismic event probability of a given magnitude in a given region. Predictive systems of seismological phenomena and soft computing techniques can therefore help to obtain good choices for the citizens' safety when a given danger threshold is exceeded.
\end{abstract}

In this regard, the possibility to have significant and reliable displacement data of network points repeated over time deriving from GPS monitoring networks set up across the monitored faults, as well as the use and implementation of dynamic GIS that also use "predictive" layers based on the use of neural networks and soft computing, can provide on one hand databases useful for the implementation of predictive models (soft computing techniques that use displacements as input data) and on the other hand valid information on propagation of the isoseismal (starting from information relating to the study area, the hypocenter of the considered earthquakes and the seismic intensity determined according to standard procedures).

The objective of the following work is therefore to present and analyze the results of a prototypal predictive system developed by the Reggio Calabria Geomatics Laboratory. This prototype use a GIS systems and soft computing techniques. It allows on one hand to calculate the probability of seismic event's occurrence (event of known intensity that follow another also known) and on the other to identify and predict the isoseismal's propagation. The Gis system incorporate and implement rigorous methodologies for displacements computing on GPS networks repeated over time, while the soft computing uses the surface's displacements points monitored by a GPS network and the events that took place in their surroundings.

The methodology was tested in the central Tyrrhenian area of Calabria (where there are a series of active faults). focusing in particular on the Falerna -Fuscaldo fault (Italy).

Key-Words: - GPS, GIS, Neural Network, Earthquake, Monitoring,

Received: December 13, 2020. Revised: April 19, 2021. Accepted: April 28, 2021. Published: May 5, 2021.

\section{Introduction}

Among the Mediterranean countries, Italy has one of the highest seismic risk both for the frequency of the earthquakes that have historically struck its territory, and for the intensity that some of them have reached [1].

Even now, earthquake prediction is impossible: we know that an earthquake, in fact, is the result of a complex system of events and factors occurring below the earth's crust. Timing and magnitude of a seismic event, for example, depend on the energy stored in a point of the fault and the level of "stress" which that precise point of the earth's crust reaches. Accurate measurements of the mentioned values would require kilometric drilling under the earth's surface; would also require the installation of extremely sensitive sensors, that have not yet been developed [2]. 
Nevertheless, earthquakes happen in clusters: major aftershocks are prefaced by minors tremors as "warning". When the proximity, frequency and intensity of these shocks increase, a seismic swarm occurs, a real wake-up call for natural disaster experts and seismologists.

In this regard, it should be noted that (through geomatic techniques) it is now possible to easily measure the surface movements of well-defined points, straddling active faults (using rigorous methodologies to compute the vertexes displacements significance highlighted in time and space).

On the other hand, the use of soft computing techniques for predictive purposes (successful used in many other scientific and application sectors) is also leading to interesting contributions in the field of seismic prevention.

GIS systems, then, thanks to their potential for managing and displaying data as well as the possibility of being implemented in an open way, certainly provide useful contributions in relation to the study of the topics proposed in the field of monitoring and prevention

The integrated use of these methodologies (geomatics / soft computing) can therefore provide a valuable contribution in relation to the prevention of seismic risk

The methodology proposed in this note, thanks to the use of a GIS platform, would allow on one hand the evaluation of the "short-term seismic hazard" (in order to obtain a percentage value with respect to the probability that a given earthquake will occur on a given area) and, on the other hand, the isoseismal prediction and estimation related to the study area.

The potential provided by the proposed methodology could help both the authorities (in order to prepare the emergency machine in time and to ensure the physical safety of citizens), and the citizens (that could constantly be informed about the risks that occur in real time).

Currently there is no general methodology for earthquake prediction. Moreover, there is still no consensus in science community on whether it is possible to find a solution of this problem. However, rapid development of machine learning methods and successful application of these methods to various kinds of problems indicates that these technologies could help to extract hidden patterns and make accurate predictions. Some actual research are focused on precursor study: for instance, an application regard to the discovery of the small quakes aftershocks patterns that follow a large earthquake ( mainshock) and occur in the same area. One of the most recent examples is discussed in [3], where an artificial neural network in trained on more than 130.000 mainshock-aftershock pairs in order to model aftershock distribution and outperforms the classic approach to this task.

Previous studies have applied several statistical and ML (Machine Learning) algorithms for the classification of aftershocks. For example, Kortström et al. [4] classified blast-related and nature-related aftershocks and sources of noise using an automated support vector machine (SVM) technique in regions that suffer from sparse seismic networks; their results showed that man-made (explosions) and natural (seismic) aftershocks can be identified with a high level of reliability using their approach. Discrimination analysis was used by Che et al. [5] to identify an explosion-induced event in North Korea. In addition, Lyubushin et al. [6] classified seismic records acquired from the Aswan Dam region in Egypt as either natural events or blasts using the spectral support widths method. Rouet-Leduc et al. [7] investigated laboratory earthquakes to predict the failure time of a fault based on acoustical information and an ML method called random forest (RDF) classification. A few works have attempted to predict the locations of earthquakes based on an adaptive neural fuzzy inference system (ANFIS) and a supervised radial basis function (RBF) network $[8,9]$.

\subsection{Geo-topographic characteristics of the fault}

As is well known, Calabria is in a very complex geodynamic position with a high seismic risk. In fact, it has a very high seismic risk (due to the frequency and intensity of phenomena that occurred in historical times), a very high vulnerability (due to the fragility of the building, infrastructures, industrial, production and a very high exposure (due to density housing and the presence of a historical, artistic and monumental heritage in areas affected by active faults). For this reason, Calabria is at high seismic risk, in terms of potential victims, damage to buildings and direct and indirect costs [10].

Central Calabria is crossed by a system of faults in full activity (red lines in fig. 1), which develops from the "Crati Valley", passes through the Strait of Messina and ends in eastern Sicily [11]. These faults (represent high seismic risk sectors) caused almost all the catastrophic earthquakes that hit Calabria in historical times: the "Crati Valley" earthquake of 1183, the "Reggio and Messina" earthquake of 1908, the earthquake crisis of southern Calabria in 1783, the earthquakes in central Calabria in 1638 and 1905, the "Cosentino" earthquakes of 1835, 1854 and 1870.[12] 
The Fuscaldo Falerna fault (CS4) (Figure 1) is the westernmost Calabrian fault located almost at the western coast. It develops for a total length of about $55 \mathrm{~km}$, with a maximum credible break of $20 \mathrm{~km}$. The geometry is mostly planar with direct kinematics and a paleoseismicity that varies from 0.2 to $0.5 \mathrm{~mm} /$ year.

The San Marco Argentano - Domanico fault (CS2) (Figure 1) is located on the west side, almost in correspondence with the west coast and parallel to the CS4. It develops for a total length of about $50 \mathrm{~km}$, with a maximum credible break of $25 \mathrm{~km}$. The geometry is mostly listric with direct kinematics and a paleoseismicity that varies from 0.5 to $2 \mathrm{~mm} /$ year.

The Piano Lago fault (CS5) (Figure 1) is located on the west side, almost in correspondence with the west coast, parallel to the CS4 and CS2. It develops for a total length of about $15 \mathrm{~km}$, with a maximum credible break of $10 \mathrm{~km}$. The geometry is mostly planar (synthetic - antithetical) with direct kinematics and a paleoseismicity ranging from 0.2 to $0.5 \mathrm{~mm} /$ year.

The Valle del Savuto - Decollatura fault (CS6) (Figure 1) is located on the west side, almost in correspondence with the west coast, parallel to the CS4 and continuously to the CS5. It develops for a total length of about $30 \mathrm{~km}$, with a maximum credible break of $8 \mathrm{~km}$. The geometry is mostly planar (synthetic - antithetical) with direct kinematics and a paleoseismicity ranging from 0.2 to $0.5 \mathrm{~mm} /$ year.

The Lamezia Catanzaro fault (CS18) (Figure 1) is located on the junction of the two cities (from which it takes its name), orthogonal to CS4. It develops for a total length of about $45 \mathrm{~km}$, with a maximum credible break of $45 \mathrm{~km}$. The geometry is mostly planar (synthetic - antithetical) with direct kinematics and a paleoseismicity ranging from 0.2 to 0.5 $\mathrm{mm} /$ year.

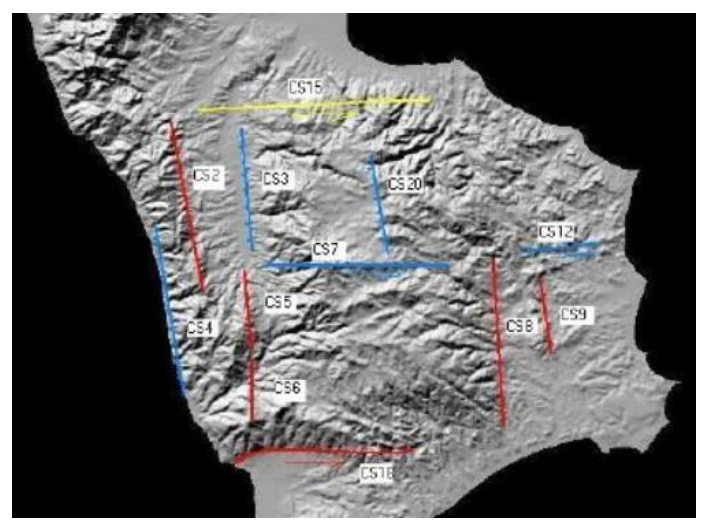

a)

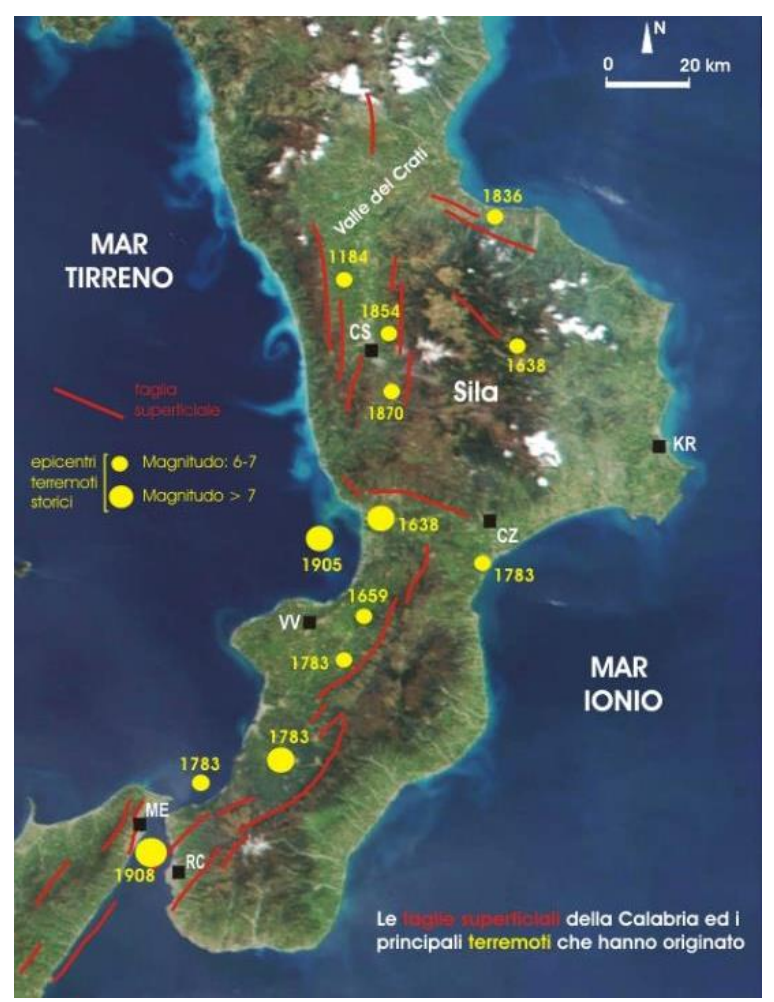

b)

Figure 1 - Central Calabria a) Active faults (red) and dormant faults (blue) b) Active faults (red) and Earthquake (yellow).

\section{GPS/GIS data}

As part of a monitoring project of Calabrian active faults and consequent capable faults database (DB) updating, the Geomatics laboratory of the "Mediterranea" University is working on a monitoring project related to several faults present in the Calabrian territory, through survey, monitoring and control activities that are organized into three portion of regional territory (Northern - Central Southern).

Specifically, this note focuses on the central Tyrrhenian part of Calabria (San Marco Argentano fault - Domanico, Piano Lago fault Valle del Savuto fault - Lamezia Catanzaro fault and Fuscaldo Falerna fault), focusing particularly on the analysis of the Fuscaldo Falerna fault.

In general, the survey activities carried out by the Geomatics Laboratory provided the establishment on these 5 faults of "mobile" GNSS networks consisting respectively of single GPS networks (on each fault) connected to other external vertices (different for the 5 networks) that act as external references for the whole area.

In particular, the Fuscaldo Falerna fault (CS4) consists of 8 vertices. 
The San Marco Argentano - Domanico fault (CS2) consists of 6 vertices.

The Piano Lago fault (CS5) consists of 4 vertices.

The Valle del Savuto - Decollatura fault (CS6) consists of 4 vertices

The Lamezia Catanzaro fault (CS18) consists of 8 vertices.

The acquisition of Gps data was carried out so as regular and constant as possible over time from 2010 (weekly / monthly) with particular reference to the Fuscaldo - Falerna fault (CS4) in order to have a database as broad as possible.

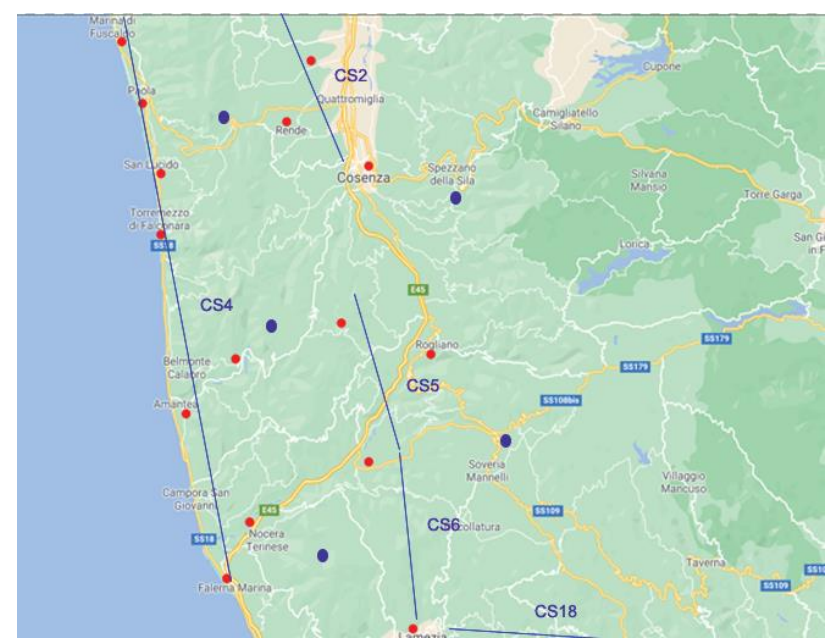

Figure 2 - Faults CS2 CS4 CS5 CS6 and CS18 (blue lines), the measured vertices (in red) and vertices on stable area (in blue).

As mentioned, the 5 networks consist of some points straddling each fault and others positioned on the external area, (located in a "presumably" stable area), two of them on the east side and one on the west side (Fig.2).

As is well known (with particular reference to active networks for monitoring and controlling active faults) a rigorous data acquisition methodology would imply the simultaneous use of a certain number of GPS receivers coinciding with the number of network cornerstones and the materialization on rock of the station points (vertices of the network) by means of pillars in order to reduce the centering error below one millimeter (the use of a steel antenna port, properly designed, allows to meet the stringent requirements mentioned above) Moreover, an optimal condition would provide simultaneous measurements on consecutive days, with observation windows of eight hours for each day, cut-off angle of 15 degrees and sampling time of 15 hours. [13-14]

Unfortunately, due to the lack of both funds and instruments (3 GPS receivers) and personnel for such a long period of time, the measurement campaigns carried out by the Geomatics Laboratory (from 2010 to date monthly and / or weekly), have used the triangulation method on three network points (using a "mobile network" without to perform forced centering with a steel antenna as originally designed), however covering all the network vertices (even if sometimes, for organizational/economical reasons, the surveys were carry out also in different periods from each other).

Although the survey methodology used (all the established networks are as already said "mobile" networks as the vertices are not actually materialized on site) provides a lower precision than the strictly hypothesized and usable precision (in [15] high standards for the subsequent global adjustment analysis of the test network are shown).

Perhaps in the future having a number of GPS receivers and staff equal to the number of network points it hoped to have a set of rigorous temporal series measures in order to improve the results that we could obtained with what is today available.

Rigorous adjustment of the entire network, then, allows us to obtain the coordinates of the network points relating to the different measurement periods.

In fact, the subsequent use of rigorous statistical techniques [16] (for the computing of the significance of the displacements deriving from GPS networks repeated over time having a certain number of common points without having a priori information on their stability available), allows to identify a stable DATUM and then to rigorously calculate the effective displacements significance of the network points highlighted over time (final aim of the analysis of space / time monitoring).

Referring (for example) to the Fuscaldo Falerna network, Tables 1 and 2 respectively show an example of estimated coordinates of some network points and the statistics and parameters obtained from the adjustment in several years [17].

Table 1 - Coordinates of some network points.

Table 1 - Coordinates of some network points.
\begin{tabular}{|c|c|c|c|c|c|c|}
\hline STAZIONE & $\mathbf{X}(\mathbf{m})$ & $\boldsymbol{\sigma} \mathbf{X}$ & $\mathbf{Y}(\mathbf{m})$ & $\boldsymbol{\sigma} \mathbf{~ y}$ & $\mathbf{Z}(\mathbf{m})$ & $\boldsymbol{\sigma} \mathbf{~}$ \\
\hline & & & & & & \\
Fuscaldo & 4765948,703 & 0.012 & 3859389,163 & 0.009 & 1746731,312 & 0.0002 \\
\hline Paola & 4765955,427 & 0.008 & 3859394,607 & 0.017 & 1746733,792 & 0.0002 \\
\hline & & & & & & \\
San Lucido & 4765952,438 & 0.011 & 3859392,188 & 0.015 & 1746732,690 & 0.0002 \\
\hline & & & & & & \\
Falerna & 4832579,969 & 0.014 & 3775625,269 & 0.005 & 1746731,863 & 0.0002 \\
\hline
\end{tabular}

Table 2 - Global adjustment parameters.

\begin{tabular}{|c|c|c|c|c|c|}
\hline & $\widehat{\boldsymbol{\sigma}}_{\mathbf{0}}$ & $\chi 2 \mathrm{SP}$ & $\chi \mathbf{2 9 5 \%}$ & $\operatorname{Smax}(\mathrm{m})$ & $\operatorname{Smed}(\mathrm{m})$ \\
\hline $\mathbf{2 0 1 0}$ & 1.11 & 70.3 & 71.2 & 0.052 & 0.019 \\
\hline
\end{tabular}




\begin{tabular}{|c|c|c|c|c|c|}
\hline $\mathbf{2 0 1 1}$ & 1.12 & 77.8 & 76.4 & 0.053 & 0.016 \\
\hline 2012 & 1.12 & 80.5 & 82.1 & 0.051 & 0.014 \\
\hline 2013 & 1.10 & 75.2 & 81.4 & 0.049 & 0.021 \\
\hline 2014 & 1.11 & 75.6 & 84.0 & 0.048 & 0.022 \\
\hline 2015 & 1.12 & 79.4 & 79.9 & 0.040 & 0.024 \\
\hline 2016 & 1.13 & 81.1 & 81.2 & 0.045 & 0.020 \\
\hline 2017 & 1.12 & 79.5 & 85.7 & 0.032 & 0.018 \\
\hline 2018 & 1.11 & 80.9 & 88.4 & 0.038 & 0.017 \\
\hline 2019 & 1.11 & 78.1 & 82.5 & 0.037 & 0.019 \\
\hline$\widehat{\sigma}_{0}$ & $\begin{array}{l}\text { Estimation of Root Mean Square of the unit } \\
\text { weight }\end{array}$ \\
$\mathrm{X}^{2} \mathrm{sP}$ \\
$\mathrm{X}^{2} 95 \%$
\end{tabular}

Once we have available the coordinates of the vertices of the network in the various epochs as well as all the statistical parameters deriving from the different rigorous adjustment of the networks carried out over time, the analysis aim is the significance evaluation of coordinate deviations in two different GPS surveys with some points in common, even without a pre-defined stability information. The basis of the analysis is the presence of the Cartesian elements of the GPS bases and of their covariance matrix resulting from the elaboration of the GPS phase measurements, already cleaned from possible outliers and defined in the same reference system. The result of this analysis therefore consists in the separation of the common points between the two surveys into two groups:

- points with non-significant coordinate variations (final datum)

- points with significant coordinate changes starting from the differences coordinates $\delta_{\mathrm{X}}$ estimated with their covariance matrix $\mathrm{C}_{\delta \delta}$ obtained from adjustment with minimum constraints of the two surveys. For this purpose, we use the procedure illustrated in [18] that allows us to select the resulting datum automatically by using an iterative procedure that is based on the classical Fisher test under the assumption of normal distribution of observations and, thus, of differences in coordinates. In this routine, starting from these obtained differences in an initial datum that contains part or all of the network points (these are adjustments with minimum constraints in which the barycenter of the points encompassed in the datum is fixed), we test the differences of the three coordinates for each point, excluding from the datum the points for which such differences are meaningful; the procedure stops once the datum is no longer modified from one iteration to the next.

The above activities have been implemented within an "open" dynamic GIS [19] (Fig 3) which therefore allows to determine the significance of the displacements of the points GPS network (which have common points without a priori information on the stability of the network point coordinates) repeated over time.

In detail, through the GIS potential it is possible to process, to have available and to view:

- The coordinates of the network points deriving from a "free" or "constrained" network adjustment;

- the DATUM (set of statistically stable network points) identified through statistical tests (Fisher's test) (Fig. 3 a);

- the estimate of the new coordinates of the network points in the identified DATUM (transformation) (Fig 3 b);

- the displacements of the network points deriving from an adjustment of the bound networks, in the identified DATUM (Fig $3 \mathrm{c}$ ).

Fig. 3 shows the result of the proposed methodology relating to the Fuscaldo Falerna fault area between 2018 and 2019 where the red dots represent the measured vertices, the blue dots represent the chosen vertices on external stable areas; the blue lines represent the faults; the red crosses instead represent the transformation of the coordinates of the network vertices in the identified Datum; the red circles and arrows represent the measured and calculated displacements. 


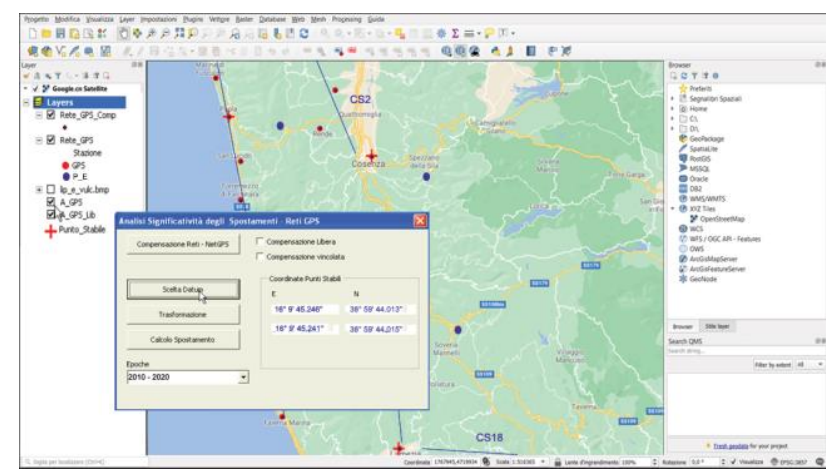

a)

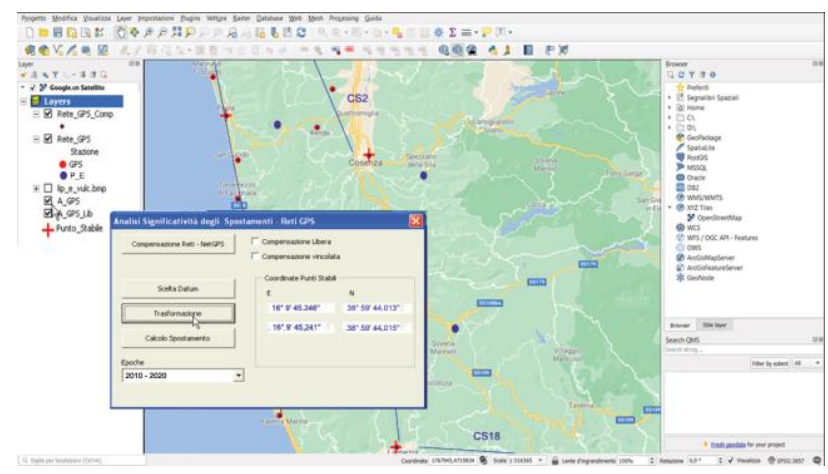

b)

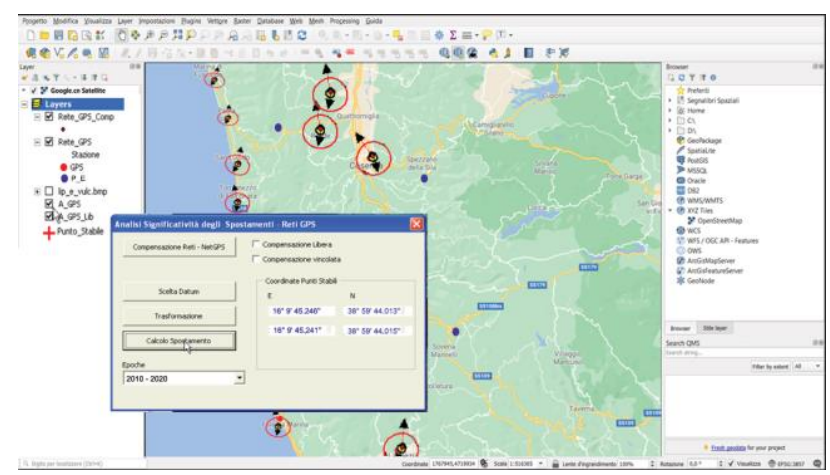

c)

Figure 3 - a) Identification of the DATUM (red crosses); b) Transformation of the coordinates of the network vertices in the identified Datum; c) Computing of displacements in the selected Datum on all faults.

In fig. 4, only the displacements calculated in the selected DATUM relating to the Fuscaldo Falerna fault in the period between 2018 and 2019 are highlighted.

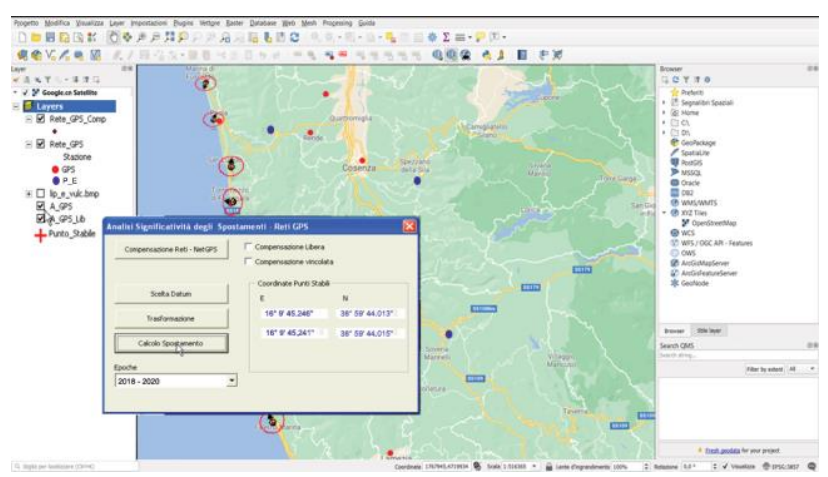

Figure 4 - Calculation of displacements in the Datum selected on the Fuscaldo Falerna fault example of representation of displacements between 2018 and 2019.

The figures $5(\mathrm{a}, \mathrm{b}, \mathrm{c})$ instead show the graphs relating to some principal vertices displacements over time (shown in Table 1) of the Fuscaldo Falerna network (we reported as example only Fuscaldo x coordinate, Paola y coordinate and San Lucido z coordinate.)

Change of $X$ coordinate

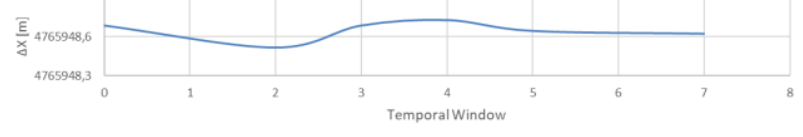

a)

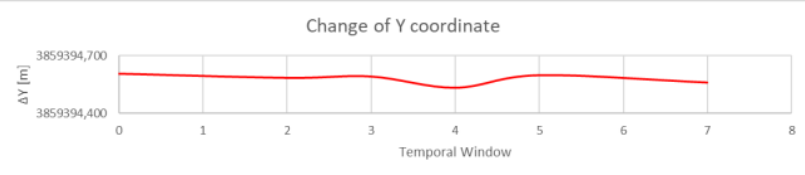

b)

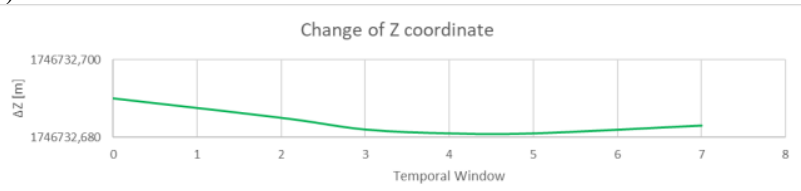

c)

Figure 5 - displacements over the time of: a) Fuscaldo $x$ coordinate, b) Paola y coordinate, c) San Lucido z coordinate.

\subsection{Seismic data}

The seismic data used in our work (Figs. 6, 7, 8) were those provided by the National Institute of Geophysics and Volcanology (seismic surveys carried out throughout the country for 24 hours a day, and for 7 days a week), regarding:

- events that occurred around (30 km radius) in relation to the study area,

- a time window from 2010 to today,

- seismic events of magnitude greater than 3 ,

- seismic events of magnitude less than 3 . 


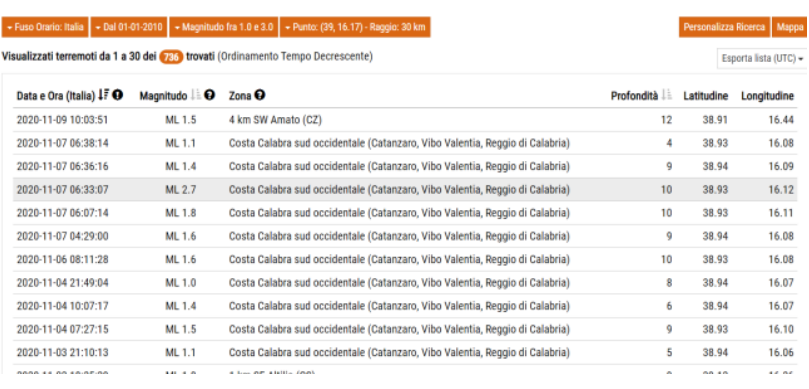

Figure 6 - Example of seismic events that took place around (radius $30 \mathrm{~km}$ ) of Falerna Fuscaldo.

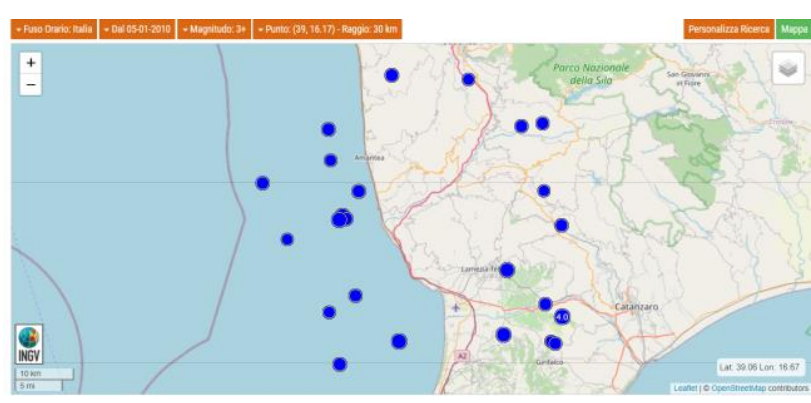

Figure 7- Seismic events of magnitude greater than 3 from 2010 to today.

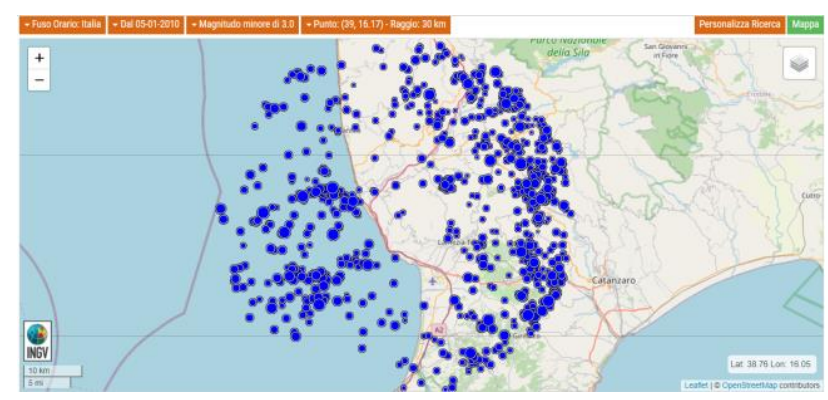

Figure 8 - Seismic events of magnitude less than 3 from 2010 to today.

\section{Prediction of large aftershock sequences}

Using a neural network, we tried to connect the surface displacement data (GPS network) to the seismic data, to verify the possibility to create a risk map, that shows the probability of a new earthquake and its magnitude (greater or less than 3), in a defined area, upon the occurrence of a seismic event [30].

The occurrence of a major earthquake almost always triggers secondary seismic tremors, known as aftershocks. The behavior of aftershocks (that are known to be as dangerous as main shock sequences) resembles that of a decaying probability model (gradually decreasing values). The magnitude of an aftershock depends significantly on the time of occurrence and the magnitude of the main shock [3132-33].
The data analysis shows that the highest value of the aftershock was observed away from the main shock, suggesting that the transfer of stress from the main shock to the aftershock is static.

From the statistical study of the aftershock sequences, it emerge that surface events are generally not events related to surface movements, being also influenced by the distance of the epicenters from the the earth surface [34].

As known, neural networks are non-linear structures of statistical data organized as modeling tools. They can be used to simulate complex relationships between inputs and outputs that other analytic functions cannot represent [35-36].

Our goal was to test a machine learning classifier able to predict the correct risk class (low entity or high entity) based on the $\Delta x, \Delta y$ and $\Delta z$ coordinates (displacement of network points and epicenter of the earthquake) [37].

In this regard, a 9-level neural network was created with an input level, a hidden level and an output level. The number of nodes in the input layer was determined by the dimensionality of our data. Similarly, the number of nodes in the output layer was also determined by the number of classes we have. The network input are therefore the $\Delta \mathrm{x}, \Delta \mathrm{y}$, and $\Delta \mathrm{z}$ coordinates (displacement of the network points and epicenter of the earthquake) and its output will be a different probability value, respectively for class 0 ("magnitude <3") and for class 1 ( "magnitude> 3").

The training technique used to implement the network is the "reinforcement learning", in which an appropriate algorithm tries to identify a certain modus operandi, starting from a process of observation of the external environment; in particular, every action has an impact on the environment and the environment produces feedback that guides the algorithm itself in the learning process. Such a class of problems requires a perceptive agent that explores an environment in which it learns a series of actions. The environment itself provides an incentive or a disincentive in response, at random [38-39]. The reinforcement learning algorithms ultimately attempt to determine choices to maximize the cumulative incentives received by the agent during the problem analysis. Reinforcement learning differs from supervised learning because it never presents input-output pairs of known examples, nor does it explicitly correct itself with suboptimal actions. Furthermore, the algorithm is focused on online performance, that involves the balancing and the exploration of 
unknown situations with the exploitation of current knowledge [40].

Furthermore, it is possible to choose the dimensionality (number of nodes) of the hidden layer. The more nodes we insert in the hidden layer, the more complex the functions we will be able to adapt. But a higher dimensionality has a high computational cost. Indeed, we need more calculations to make predictions and learn network parameters.

In our analysis, to activate the hidden layer, we have chosen the fuction "tanh" as the activation function. It is an unilinear activation function that allows us to fit non-linear hypotheses. A good property of these functions is that their derivative can be calculated using the value of the original function.

Since we want our network to generate probabilities, the trigger function for the output level will be the function "softmax", which is simply a way to convert raw scores into probabilities.

Our network makes estimates using the forward propagation alghoritm, that is a series of array multiplications and the application of the activation functions we defined above (Fig. 9). We need to find parameters that minimize the error on our training data, to let our network learn the parameters. To define the error we use the "softmax" output function (the categorical loss of cross entropy also known as negative $\log$ probability). Subsequently to define if the system predict the wrong risk class we compare the gap between the parameters in the Training DB and the forecasting parameters.

The farther away are the two probability distributions $y$ (the correct labels) and $\mathrm{y}^{\wedge}$ (our predictions) greater is our gap. By finding parameters that minimize our gap we maximize the likelihood of our training data.

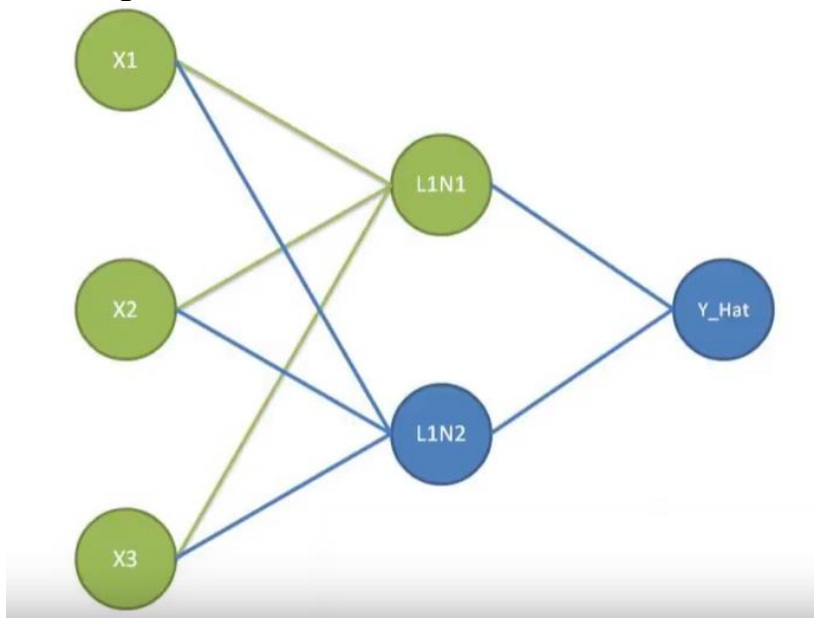

Figure 9 - Forward propagation scheme
Then, taking into account the large amount of network point displacement data resulting from the processing of GPS/GIS data and the equally large amount of seismic data provided by the INGV), the neural network tests, in a given region (study area) the relative probability of the occurrence of a seismic event with a magnitude greater or less than 3 in relation to the occurrence of a "significant" event recorded by the INGV around $50 \mathrm{~km}$ from the study area [40-41].

The result can be displayed on GIS through suitable functions (Fig.10).

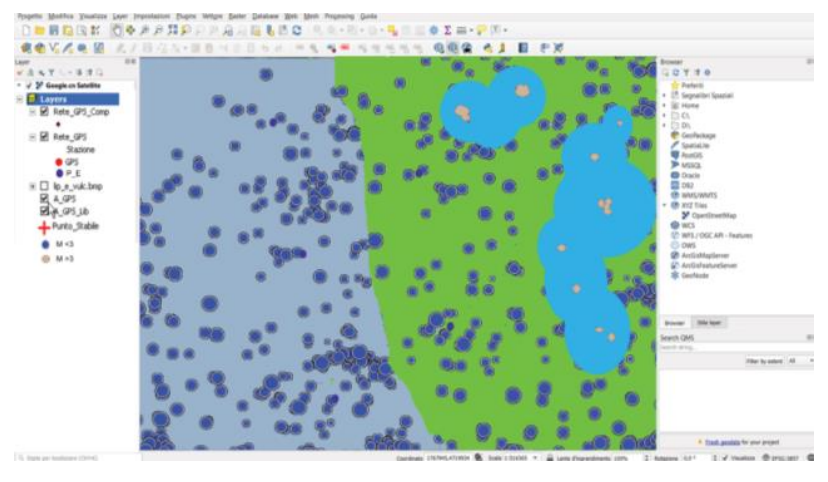

Figure 10 - Risk map (green area: area with probability of magnitude $<3$, Blue area: area with probability of magnitude $>3$; red: earthquake magnitude $<3$; dark blue: earthquake magnitude $>$ $3)$.

In Fig.10, for example, is reported the area of the Fuscaldo Falerna fault that shows the forecast of occurrence over a two-week period; in particular in green is reported the area with a probability of magnitude less than 3 and in blue the area with a probability of magnitude greater than 3 .

\section{Isoseismal generation}

In order to provide information on the propagation of isosisms starting from information relating to the study area, the hypocenter of the earthquakes considered and the seismic intensity determined according to standard procedures, a methodology was proposed that integrates the use of Neural networks through the generation of an informative layer with Artificial Intelligence (defined with the name of "OverlayAI") [42]

A hazard map is therefore proposed, obtained jointly using an artificial intelligence operator (OverlayAI) integrated in the GIS environment to determine the attenuation of the macroseismic intensity in the study area.

The generation of a seismic hazard map as proposed by the aythors takes place in various phases, using different data structures organized as GIS layers [43].

In particular we use: 
- a layer of the epicenters where the point features are referred to the epicenters of appropriate seismic events collected through the historical database of the National Institute of Geophysics and Volcanology (INGV) (fig 10);

- a layer that classify the geology of the examined territory (fig 13);

- a TIN layer for the altimetric representation of the territory (fig 14).

The first phase consists in the selection by the user of one or more epicenters and in the consequent generation of a layer with polygonal features where the boundaries of the polygons are the isoipses useful for the description of the attenuation of the macroseismic intensity. The operator that generates this layer was built within the GIS system with a Neural Network [34], which implicitly implements the earthquake energy propagation function. For the implemented model (fig 11) it was assumed that this function has the following dependencies:

$P_{j}(l)=f\left[p_{A}, M_{j}(l), H_{j}(l), \theta_{j}, P_{j}(l-\Delta S), \Delta \omega\right]$

\section{Where}

$\theta_{j}$ is the angle indicating the direction along which the $\mathrm{j}$-th simulation is performed;

$p_{A}$ is the epicenter of the seismic event;

$l$ is the distance of a generic point from the epicenter; $M_{j}(l)$ and $H_{j}(l)$ respectively represent the coding (carried out through a progressive natural number) of the surface geological layer and the altitude above sea level of a point located at a distance $\mathrm{D}$ from the epicenter and on the $\mathrm{j}$-th line;

$P_{j}(l)$, is the seismic wavefront power associated to the point of polar coordinates $1, \theta \mathrm{j}$.

$P_{j}(l-\Delta S)$ is the seismic wavefront power associated with the point lying on the jth directrix, but at the distance $1-\Delta \mathrm{S}$.

$\Delta S$, finally, is a constant step used by the solution algorithm to determine the points for which the seismic wavefront power will be calculated gradually.

Specifically, the activities carried out by the (iterative) algorithm, proposed for tracing the isoseismal, are carried out in the manner illustrated below (Fig.11).

Starting from the supposed power already calculated in a point having coordinates $l_{i, j}, \theta_{j}\left(l_{i, j}\right.$ is the distance from the epicenter of a point lying on the $j$-th directrix and, at the same time, on the $\mathrm{i}$-th isosism) and expressed as $P_{j}\left(l_{i, j}\right)$, the power $P_{j}\left(l_{i, j}+\Delta S\right)$ is calculated at the point of coordinates $l_{i, j}+\Delta S, \theta j$ (in particular for points 1 and 2: $1_{1,2}+\Delta S, \theta_{2}$ ). At this point, the power $P_{j}\left(l_{i, j}+\Delta S\right)$ is compared with the power value $P_{j-1}\left(l i+1,{ }_{j-1}\right)$ (in particular for the point $\left.1 P_{I}\left(l_{2,1}\right)\right)$. If this last value is greater of the value calculated with the previous iteration, we proceed iteratively along the $\mathrm{j}$-th directrix (in figure $j=2$ ), until we found a point, whose power values are comparable according with (1). The power values that are calculated iteratively are obtained from a network neural that implements function (2).

$$
\frac{P_{j}\left(l_{i, j}+\Delta S\right)}{P_{j-1}\left(l_{i+1, j-1}\right)} \cong 0.02
$$

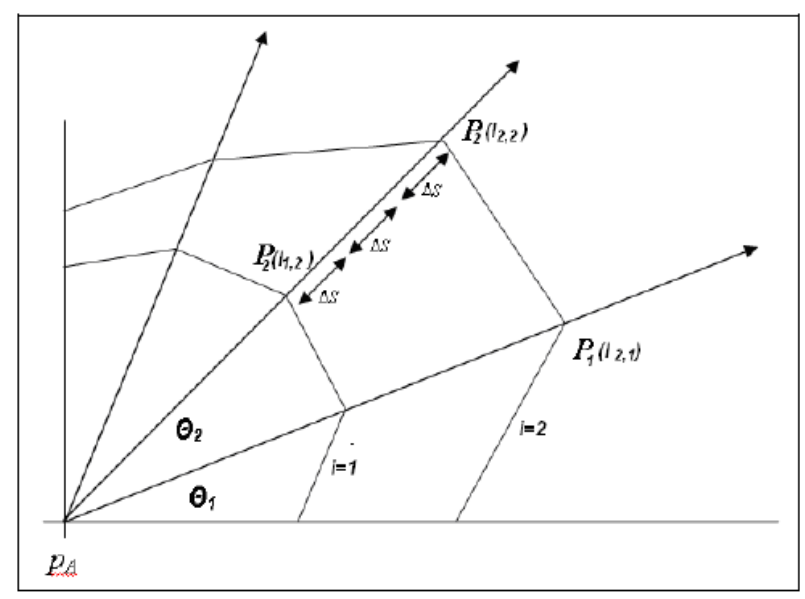

Figure 11 - Tracking of isoseismal by the OverlayAI operator.

In this case, the power considered for the purpose of tracing the isoseismal is represented by the seismic intensity relative to the magnitude of the individual earthquakes, (INGV DATA), considering the varied morphology of the Calabrian land, evaluating the height of the various points from the sea level, as well as the geological nature of the different types of materials present in the area considered.

The types of material are very important (they constitute the results of sedimentations in the various geological periods and therefore present a different behavior to the reflection and / or transmission of seismic waves) and in this regard, in our work the different material typology was highlighted through an appropriate numerical coding. This coding was implemented by associating a positive integer to each type of material.

An example of the results obtained from the experiments carried out is shown in Fig.12, which highlights two layers generated with the OverlayAI operator and modeling the isoseismal in the study area. 


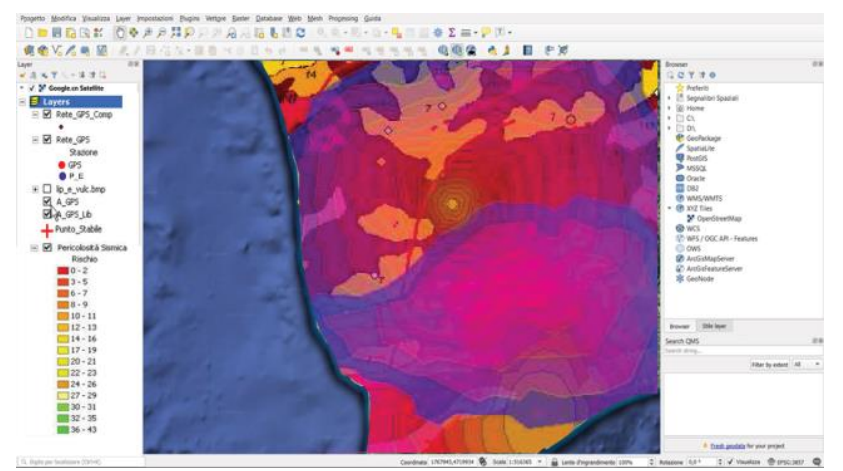

Figure 12 - Layer generated with Overlay operator implemented.

Figure 13 shows the geological map of the Fuscaldo area (Paola - San Lucido quadrant) while Figure 14 shows, a portion of the TIN layer used to take into account the effect of the altitudes on the propagation of the seismic front.

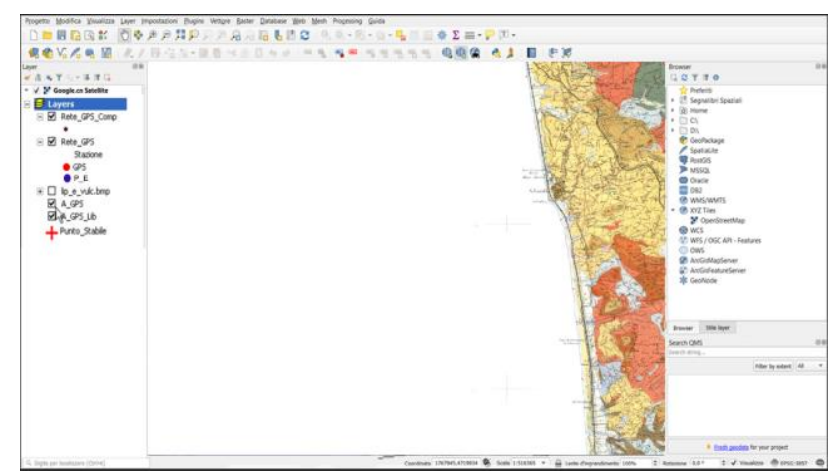

Figure 13 - Geological Layer.

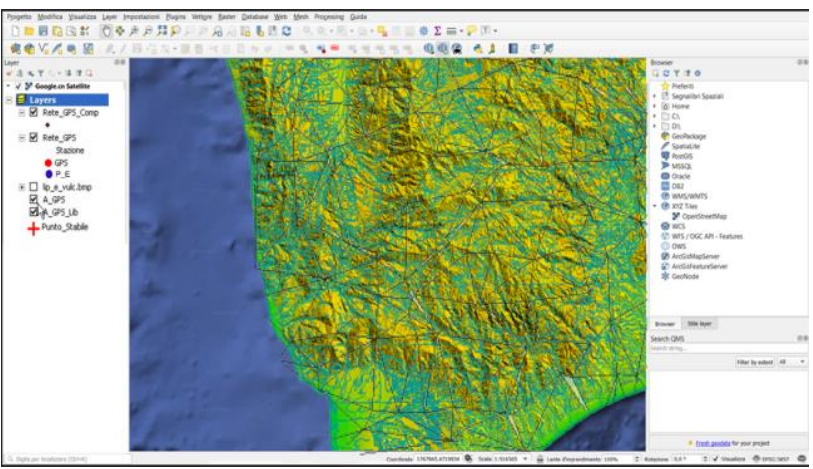

Figure 14 - TIN Layer.

The last phase for the calculation of the hazard map is resolved in carrying out a standard Geoprocessing Intersect operation among all the layers (generated by OverlayAI) with polygons delimited by isoseismal, and whose features have the calculated attribute from the Neural Network in the first phase (the intensity of the earthquake is classified for the surface of the polygon itself). This operation generates a layer where the features are many polygons obtained from the intersection of the polygons of the layers of the isoseismal (Fig.15).

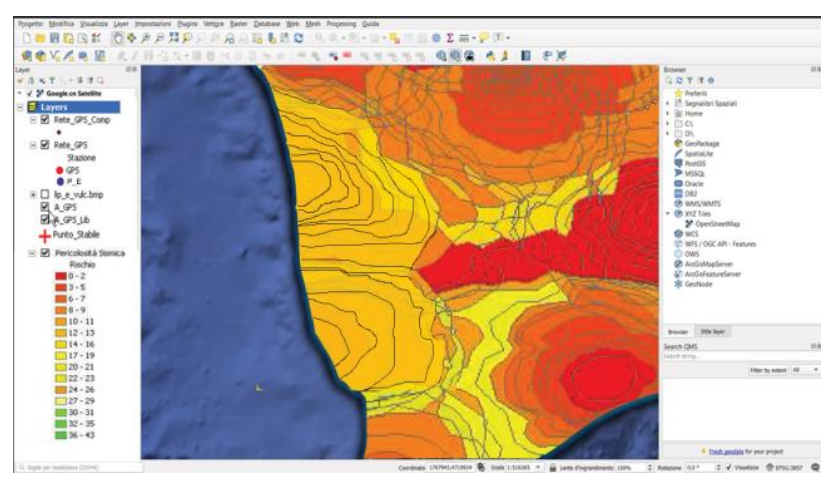

Figure 15 - Isoseismal layer

The layer resulting from this operation has an attribute where is inserted an index proportional to the sum of the indices representing the powers of the layers participating in the same Intersect operation. A thus made layer classifies the areas according to the index mentioned above; the meaning of this mapping therefore refers to the probability that a given area is hit by a seismic event of considerable intensity. For example, a given center, although close to a considerable number of "potential" epicenters, may be less at risk than a center far from these epicenters but delimited by a geological layer (together with other factors) which does not dissipate the energy of the earthquake [35.].

In Figure 15, aggregated areas for forecasted characteristics are reported in different color scales .

\section{Discussions}

Preliminary, it should be noted that the results obtained derive from a preliminary experimental analysis carried out exclusively in order to create and test a scientific methodology as rigorous as possible Of course, the proposed application requires the use of additional data (acquired in a rigorous manner through the use of networks materialized on site with stable pillars as materialized vertices and with forced centering) and refinements of the neural network used today, in order to provide potentially valid results also for application purposes and not only from the point of methodological experimentation.

As is well known, it is not yet possible to predict earthquakes and there are many variables to take in account [36]. Consequently, the link or the "unique" correlation between surface movements and earthquakes is certainly reductive. Infact, it is well known that many parameters play a fundamental role in the field of earthquake prevention:

- geophysical precursors: anomalies in the speed and characteristics of the seismic waves $P$ and $S$ and variations in the magnetic 
and electrical characteristics of rocks and the atmosphere;

- seismological precursors: before a major seismic event can occur a series of microtremors (detectable only by instruments) or a change in the distribution of seismicity;

- geodetic precursors: changes in altitude, position, inclination of parts of the soil surface and velocity of the measured displacements;

- geochemical precursors: variation of the concentration in water underground and in the ground gases of some chemical elements radioactive, including radon gas;

- hydrological precursors: variation of the subsoil level of the acquifer, measured in the wells,

and so on.

These parameters have not yet been taken into account experimentation.

In relation to the determination of the isoseismal, it should also be said and emphasized that the different behavior of each single geographical point in the transmission of seismic waves is due not only to the geo-morphological characteristics, but also to the type (epicentral, hypocentral, etc. .) and the magnitude of the earthquake. This dependence was not taken into account in this study because as mentioned, its still merely preliminary phase.

It is also worth noting that the neural network used and implemented for this work comes from an experimental test, initially built and tested by authors with different data and different application purposes. The neural network test used in this work is therefore certainly susceptible to improvements in order to obtain better and reliable results; in addition, it should be noted that the GPS networks are currently present on the territory in "mobile" mode without providing for any on-site vertices materialization, forced centering, and making acquisitions on quick geometries (due to economics and organization factors). In the future the whole methodology could be made more efficient reducing most of the approximations above mentioned.

However, the experimentation carried out, even if it requires further tests and analyzes, to date, unexpectedly also for authors, however, has shown that, it would seem to exist a certain link between displacements and earthquakes (which must be further studied and ascertained in order to contribute to the definition of the earthquake propagation mechanism) verified in relation to the expected earthquakes of given intensity following an already realized event of known intensity. Similarly, appreciable, seems to be, the results obtained relating to the isoseismic modeling.

\section{Conclusions}

The large number of GPS data acquired over time allows us to highlight a speed of displacements of the earth's crust in the Fuscado Falerna fault; this displacement is about $3(\mathrm{~mm} /$ year). Geological studies carried out underground show a speed of movement of 2-5 ( $\mathrm{mm} /$ year). The ambitious study of the surface deformation of the crust in the Calabrian area aims to highlight the possibility of a scientific comparison between deformations of the subsoil and surface deformations, in order to improve the knowledge of the active geo-structural fault.

Through the appropriate use of a Neural Network (specially trained and tested on historical data made available by the INGV) and soft computing techniques in general, it was possible on the one hand, to estimate the probability of occurrence of events following the realization of a given event of given intensity and on the other to proceed to the isoseismic modeling. From our application we obtained a preliminary quite good result in the context of earthquake prevention studies. In fact, the predictive obtained maps if adequately superimposed (within the proposed GIS) to socio-economic layers, allows to obtain results for the purposes of decisionmaking and to support the various local authorities for the protection and safeguarding of the population. The proposed methodology does not presume to be exhaustive nor in relation to the probability computing of events occurrence (subsequent to a given event) nor in relation to the isoseismic computing, since, both in the first and in the second case a series of simplifications have been used and more insights need to be carried out. The methodology used is however satisfactory as a starting point to be integrated with further and subsequent data and in any case it can still be considered a fast methodology for a quick evaluation (that in any case seems to provide results comparable to those obtained with more complex expensive and complete studies) of the earthquake prediction (to date, earthquake prediction is still beyond being considered an acquired and tested discipline).

The main purpose of this paper, in fact, is to introduce possible innovations in the structuring of a seismic risk map starting from the potential offered by GPS, GIS and Neural Networks. The research proposed, while presenting satisfactory results, is not to be considered exhaustive and future developments 
will necessarily have to take into account the simplifications and the highlighted problems.

\section{References:}

[1] Khan A., Gupta S., Gupta S. K., Multi-hazard disaster studies: Monitoring, detection, recovery, and management, based on emerging technologies and optimal techniques, International Journal of Disaster Risk Reduction, Vol. 47, 2020, 101642, ISSN 22124209 ,

https://doi.org/10.1016/j.ijdrr.2020.101642.

(http://www.sciencedirect.com/science/article/p ii/S2212420919310398).

[2] Barrile V., Fotia A., Seismic Risk: GPS/GIS Monitoring and Neural Network: Application to Control Active Fault in Castrovillari Area (South Italy), Archistor, 2019.

[3] Rouet-Leduc, B.; Hulbert, C.; Lubbers, N.; Barros, K.; Humphreys, C.J.; Johnson, P.A. Machine learning predicts laboratory earthquakes. Geophys. Res. Lett. 2017, 44, 9276-9282.

[4] C. Atkinson and R. Gerbig, "Flexible Deep Modeling with Melanee," Modellierung 2016, pp. 117-121, 2016.

[5] Kortström, J.; Uski, M.; Tiira, T. Automatic classification of seismic events within a regional seismograph network. Comput. Geosci. 2016, 87, 22-30.

[6] Che, I.-Y.; Jun, M.-S.; Jeon, J.-S. A compound linear discriminant method for small-magnitude seismic events and its application to the North Korea seismic event of October 9, 2006. Earth Planets Space 2007, 59, e41-e44.

[7] Lyubushin, A.; Kaláb, Z.; Lednická, M.; Mohamed, H. Discrimination of earthquakes and explosions using multi-fractal singularity spectrums properties. J. Seismol. 2013, 17, 975983.

[8] Panakkat, A.; Adeli, H. Recurrent neural network for approximate earthquake time and location prediction using multiple seismicity indicators. Comput. Aided Civ. Infrastruct. Eng. 2009, 24, 280-292.

[9] Zamani, A.; Sorbi, M.R.; Safavi, A.A. Application of neural network and ANFIS model for earthquake occurrence in Iran. Earth Sci. Inform. 2013, 6, 71-85.

[10] Barrile, V., Meduri, G. M., Bilotta, G. Monitoring and GPS controls, over time, of theactive fault in Castrovillari. Latest Trends in Energy, Environment and Development Proceedings Of 7 th International Conference on
Environmental and Geological Science and Engineering (Eg '14), Salerno, Italy, June 3-5, Energy, Environmental and Structural Engineering Series, pp. 169-175, 2014.

[11] Barzaghi, R., Determinazione dello stile di deformazione e dello stato di sforzo dell'arco Calabro, Framework Program 2000-2002, Annual Report-1st Year of Activity, 2002.

[12] Barrile, V.; Meduri G. M.; Bilotta G.; Monardi Trungadia U.; GPS-GIS and Neural Networks for Monitoring Control, Cataloging the Prediction and Prevention in Tectonically Active Areas, Procedia - Social and Behavioral Sciences, Vol. 223, Pages 909-914, 2016

[13] Betti, B., Crespi, M., Sguerso, D., Stabilità del sistema di riferimento nella determinazione di reti GPS. Bollettino Sifet, Vol.4 pp. 67-88, 1994.

[14] Barrile V., Crespi M., Compensazioni ed analisi di rilievi GPS per il controllo di deformazioni nell'area Etnea, Atti del $14^{\circ}$ Convegno del Gruppo Nazionale di Geofisica della Terra Solida, Rome, Oct. 23-25, pp. 309-318, 1995.

[15] Bernardini A., Giovinazzi S., Lagomarsino S., Parodi Vulnerabilità e previsione di danno a scala territoriale secondo una metodologia macrosismica coerente con la scala EMS-98, ANIDIS, XII Convegno Nazionale L'ingegneria Sismica in Italia, 10 a 14 Giugno Pisa, 2007.

[16] Barbarella M., Crespi M., Fiani M., Analisi statistica della significatività degli spostamenti, Atti del $13^{\circ}$ Convegno del Gruppo Nazionale di Geofisica della Terra Solida, Rome, pp. 319330, 1995.

[17] Barrile V., Meduri G. M, Bilotta G.; An open GIS for the significance analysis of displacements arising from GPS networks repeated over time: an application in the area of Castrovillari, WSEAS Transactions on Signal Processing, Vol. 10, pp. 582-591, 2014.

[18] Cinti F.R., Moro M., Pantosi D., Cucci L.A., D'Addezio, G., New constraints on the seismic history of the Castrovillari fault in the Pollino Gap (Calabria, Southern Italy), J. Seismol., 6, pp. 199-217, 2002

[19] Kamath R., Kamat R., Earthquake Magnitude Prediction for Andaman-Nicobar Islands: Adaptive Neuro Fuzzy Modeling with Fuzzy Subtractive Clustering Approach, Journal of Chemical and Pharmaceutical Science, Vol. 10, No. 3, 2017

[20] Asim K.M., Idris A., Iqbal T., Martínez-Álvarez F. Earthquake prediction model using support vector regressor and hybrid neural networks. PLoS One, Vol. 13, No. 7, 2018, e0199004, DOI: 10.1371/journal.pone.0199004. 
[21] Falcone R., Lima C., Martinelli E., Soft computing techniques in structural and earthquake engineering: a literature review, Engineering Structures, Vol. 207, 2020, 110269, SSN 0141-0296

[22] Aslani H. Miranda E. Probabilistic Earthquake Loss Estimation and Loss Disaggregation in Buildings, Stanford, CA, USA: Department of Civil and Environmental Engineering, Stanford University, Report No. 157, 2005.

[23] Kaufmann A., Expert Appraisements and Counter-Appraisements with Experton Processes, Analysis and Management of Uncertainty: Theory and Applications, North Holland, Amsterdam, 1992

[24] Khutsishvili I., The Combined Decision Making Method based on the Statistical and Fuzzy Analysis, Proceedings of the 3rd International Conference on Computational Intelligence, Tbilisi, Georgia, June 26-28, 2009, pp. 309- 316

[25] Ayala S., Velasco A., Kreinovich V. Soft computing ideas can help earthquake geophysics, $M C u M$, Vol. 47, No. 3, pp. 91-100, 2018, https://cyberleninka.ru/article/n/softcomputing-ideas-can-help-earthquakegeophysics (дата обращения: 21.01.2021)

[26] Sahana M., Pham B. T., Shukla M., Costache R., Thu D. X., Chakrabortty R., Satyam N., Nguyen H. D., Phong T. V., Le H. V., Pal S. C., Areendran G., Imdad K., Prakash I., Rainfall induced landslide susceptibility mapping using novel hybrid soft computing methods based on multi-layer perceptron neural network classifier, Geocarto International, 2020, DOI: $10.1080 / 10106049.2020 .1837262$.

[27] Rampone S., Valente A., Assessment of desertification vulnerability using soft computing methods, Journal of Ambient Intelligengence Humanized Computing, Vol. 10, 2019, pp. 701-707. https://doi.org/10.1007/s12652-018-0720-8.

[28] D'Amico S., Cacciola, M., Parrillo, F., Morabito, F. C., Versaci, M., \& Barrile, V., Heuristic Advances in Identifying Aftershocks in Seismic Sequences. Computers \& Geosciences, Vol. 35, pp. 245-254, 2009.

[29] Dubois D., Prade H., Théorie des Possibilités: Applications á la représentation des connaissances en informatique, Paris, Milan, Barcelone, Mexico: Masson, 1988.

[30] Juzhang Li, Fuzzy Statistics of Classification Fuzzy Mathematics, Vol. 2, No 4, 1988, pp. 107.

[31] Barrile V., Armocida G., Di Capua F., GIS application with Artificial Intelligence Algorithms for an Isoseismic Model,
Proceedings of the 2nd International Conference on Environmental and Geological Science and Engineering, 2009.

[32] Yariyan P., Zabihi H., Wolf I. D., Karami M., Amiriyan S., Earthquake risk assessment using an integrated Fuzzy Analytic Hierarchy Process with Artificial Neural Networks based on GIS: A case study of Sanandaj in Iran, International Journal of Disaster Risk Reduction, Vol. 50, 2020, 101705, ISSN 2212-4209, https://doi.org/10.1016/j.ijdrr.2020.101705.

(http://www.sciencedirect.com/science/article/p ii/S2212420920302302).

[33] Parrillo, F., D'Amico, S., Cacciola, M., Morabito, F.C., Barrile, V., Versaci, M., Caccamo, D., Neural Networks Radial Basis Function and Method Delta/Sigma for the Forecast of Strong Replicas). Atti del $24^{\circ}$ Convegno del Gruppo Nazionale di Geofisica della Terra Solida, Rome, Italy, pp. 197-200, $2005 \mathrm{~b}$

[34] Abramov V., Istomin E., Garcia J., Innovative Geoinformation Technologies Within Management of Natural Risks in Venezuela, 2018, DOI - 10.5593/sgem2018/2.2/S08.033

[35] Ferlito R., Pizza A.G., A seismic vulnerability model for urban scenarios. Quick method for evaluation of roads vulnerability in emergency, Ingegneria Sismica, Vol. 28, pp. 31-43, 2011.

\section{Contribution of individual authors to the creation of a scientific article (ghostwriting policy)}

Authors contributed equally

\section{Creative Commons Attribution \\ License 4.0 (Attribution 4.0 \\ International , CC BY 4.0)}

This article is published under the terms of the Creative Commons Attribution License 4.0 https://creativecommons.org/licenses/by/4.0/deed.en _US 